\title{
Exploring medical leader identity and its formation
}

Dr Emily Maile, Core Medical Trainee and Leadership \& Management Fellow, Health Education England East Midlands

Professor Judy McKimm, Professor of Medical Education and Director of Strategic Educational Development, Swansea University Medical School, Swansea, SA2 8PP

Dr Alex Till, Psychiatric Trainee, Health Education North West; Honorary Clinical Senior Lecturer, Swansea University Medical School

Correspondence to Dr Emily Maile: emily.maile@nhs.net

Conflict of interest: none declared

Key words: doctors, medicine, professionalism, professional identity, identity formation, leadership

Abstract Word Count: 235 / 250

Main Manuscript Word Count: 7496 / 7500 


\section{Abstract}

\section{Purpose}

'Becoming' a doctor involves the acquisition of medical knowledge, skills and professional identity. Medical Professional Identity Formation (MPIF) is complex, multi-factorial and closely linked to societal expectations, personal and social identity. Increasingly, doctors are required to engage in leadership/management involving significant identity shift.

This article explores medical professional identity (MPI) and MPIF in relation to doctors as leaders. Selected identity theories are used to enrich understanding of challenges facing doctors in leadership situations and two concepts are introduced: Medical Leader Identity (MLI) and Medical Leader Identity Formation (MLIF) and consideration given to how they can be nurtured within medical practice.

\section{Design/Methodology}

A rapid conceptual review of relevant literature was carried out to identify a set of relevant concepts and theories that could be used to develop a new conceptual framework for MLI and MLIF.

\section{Findings}

MLIF is crucial for doctors to develop as medical leaders, and like MPIF, the process begins before medical school with both identities influenced, shaped and challenged throughout doctors' careers. Individuals require support in developing awareness that their identities are multiple, nested, interconnected and change over time.

\section{Originality/Value}

This article draws on concepts from wider literature on professional identity, in relation to how doctors might develop their MLI, alongside their MPI. It offers a new perspective on MPI in the light of calls on doctors to 'become and be healthcare leaders' and introduces the new concepts of MLI and MLIF. 


\section{Introduction}

Identity is the human ability to know "who's who" and "what's what" (Jenkins, 2008), who we are, and who we are seen to be (Monrouxe, 2010). This ability to identify ourselves (the 'self') and 'others' relies upon constructing a complex multidimensional model of the world, enabling us to work out relationships between individuals and understand our identity in relation others (Jenkins, 2008).

Professional identity is how an individual sees themselves as a professional, in this instance, as a doctor (Monrouxe, 2010). Established through early socialisation (and formative years as a medical student and doctor in training) developing an appropriate professional identity is as important as developing medical knowledge and skills (Monrouxe, 2010) (Wilson, 2013). Without this, even if an individual possesses all the technical competencies and attributes of a good doctor, they may lack the confidence and courage of their convictions to truly "be" a good doctor (Monrouxe, 2010).

Most medical leadership involves physicians working in clinical practice, such as leading a clinical team (Berghout et al., 2017), with fewer doctors having formal leadership/management roles at executive (Board) level, or in education and training. Particularly in the last decade, however, a shift has occurred and involvement in leadership and management (of teams, projects, services, departments and organisations) is now viewed as vital for doctors of all levels (Dickson and Owen, 2016; Kyratsis et al., 2016). Internationally, the expectation of all doctors to engage in leadership and management is enshrined in guidance from regulators and other bodies, e.g. the United Kingdom's (UK) General Medical Council (GMC, 2012) and in Canada via the CanMEDS framework (Frank et al., 2015).

In the UK, with the increasing recognition of medical leadership as vital to the National Health Service (NHS) the Faculty of Medical Leadership and Management (FMLM) was established in 2011 (FMLM, 2018a). In Australia and New Zealand, the transition from doctor to medical leader has been formalised further by The Royal 
Australasian College of Medical Administrators' development of a Medical Leadership and Management Curriculum (Racma.edu.au, 2019) whilst in Canada the CanMEDS framework includes "leader" as one of the seven roles of physicians (Royalcollege.ca, 2019). A wide range of leadership fellowships have also been created for UK doctors in training which provides a third (growing) type of leadership: leading within, across and between services on quality or service improvement projects (Miller et al 2018). Many medical schools now also provide students with leadership development experiences (e.g. Peake and Swanwick 2018; FMLM, 2018b; Till et al 2017; Sheriff et al 2017).

In this article, selected concepts of identity and identity formation are reviewed to gain a deeper understanding of how a medical professional's identity (MPI) is developed during undergraduate and postgraduate training. Drawing from this, the concept and nature of medical leadership identity (MLI) is then introduced and explored, including how Medical Leadership Identity Formation (MLIF) can be nurtured alongside Medical Professional Identity Formation (MPIF).

\section{Rapid Conceptual Review}

As experienced practitioners, researchers and writers in the area of medical education and clinical leadership, we became interested in the concept of MLI and its formation. A potential gap in the literature was identified, particularly around underpinning conceptual frameworks which would help explain and inform practice and further research. It is acknowledged that systematic reviews have higher methodological rigour, however they are time-consuming and expensive to conduct and when the target literature is known to be relatively small, are hard to justify. Rapid reviews are used primarily in health to generate a synthesis of 'state of the art' knowledge and, whilst they use some of the "components of the systematic review process, (these) are simplified or omitted to produce information in a timely manner' (Tricco et al 2015). Whilst rapid reviews vary in rigour and methodology, more research is needed to compare the results from systematic reviews with rapid reviews (Tricco et al 2015). 
A rapid literature review process was carried out, which we have termed a 'rapid conceptual review': its aim is to identify a set of concepts, frameworks and models that can be used to develop a new conceptual framework. The rapid conceptual review is not intended to saturate the literature on a topic, nor to necessarily be reproducible, but is robust enough to provide a theoretical underpinning and evidence from the literature for the development of a model or concept, which can then be tested in the field.

Literature was identified through free-text searching Google Scholar using search terms including combinations of "junior doctor", "medical student" or "physician" plus "professional identity", "professional identity formation", "professionalism" or "leadership". Further literature was identified by scanning references and tracking citations.

\section{Inclusion Criteria}

- English Language

- Published 1995 - 2018

- Relevant to personal and social identity, medical professionalism, professional identity and its formation and leader identity formation.

\section{Identity and Identity Formation}

Identity is the human ability to know "who's who" and "what's what" (Jenkins, 2008), who we are, and who we are seen to be (Monrouxe, 2010). This ability to identify ourselves and others relies upon understanding the relationships between individuals and our identity in relation to others (Jenkins, 2008). Multiple different identity theories, grounded in sociology, psychology and philosophy, explore the concept of identity and identity formation. From the literature, two major theories were identified as particularly relevant to the development of the new concepts of MLI and MLIF: 'identity theory' and 'social identity theory'. These conceptualise the dynamic between individuals and society in terms of identity and identity formation and, whilst similarities exist, these theories are grounded in different disciplines and have differentiating features (Hogg et al., 1995) (Stets and Burke, 2000). 
Identity theory originates from sociology and focuses on an individual's identity related to the roles they play in society (Hogg et al., 1995). The 'self' is viewed as an organised set of processes which develops in every individual's mind. It can objectify its own self and categorise, classify and name itself in relation to others; a process known as 'identification' (Burke and Stets, 2009). The self is seen as an overarching identity which, through societal interactions, differentiates into multiple selves, or identities, which depend upon the role(s) in society that the individual occupies at any one time (Burke and Stets, 2009) (Hogg et al., 1995). In contrast, social identity theory has foundations in psychology and focuses on social groups, inter-group interactions and how an individual's identity is related to membership of different groups (Hogg et al., 1995). Identity is developed through a process of "selfcategorisation" where individuals identify as a member of a group through recognising similarities and differences between individuals within those groups (Hogg et al., 1995).

Boththeories view identity as formed through an understanding of one's environment and one's place within it through interaction with others (Jarvis-Selinger et al., 2012). Classical developmental theory describes identity as developing through five stages (Eriksen, 2006): individuals start to develop identity in relation to wider society; move into 'self-authoring' an identity with an understanding of groups, systems and societies, and, once they understand their own identities, can appreciate, design and create organisations and systems (Eriksen, 2006; Jarvis-Selinger et al., 2012). House (1977) suggests identity is defined at three levels relating to the interaction between social structure (e.g. mother, doctor, chief executive), interaction with others (e.g. teamworking) and personality (e.g. conscientious, outgoing) (Cote and Levine, 2002; Goldie, 2012).

Whichever model is used, there is agreement that individuals hold multiple identities, linked to roles in society or membership of different groups (Burke and Stets, 2009). An individual's professional identity, based on their job role and professional group, is one of many identities an individual holds at any one time (Roccas and Brewer, 2002). Each identity also affects the individual's behaviours and communication with others (Burford 2012) e.g. when doctors move from one country to another, professional, social and personal identities shift and challenges emerge (McKimm 
and Wilkinson 2015). Theories have developed regarding how these identities interrelateand how individuals move between identities, or hold more than one identity simultaneously. Roccas and Brewer (2002) identify four models which describe how t identities relate to each other, influence interactions and create groups. Figure 1 applies these to an example from medicine. 


\section{Model of interaction between multiple Identities}

Example: Robert, a white male doctor who holds a senior leadership position (e.g. Medical Director) within his organisation

Intersection: An individual holds more than one identity but views their identity as being the intersection of these individual elements.

Example: Robert views himself as a white male doctor in a senior leadership position, and anyone who does not fully meet these criteria does not belong to his in-group and is therefore an outsider.

Dominance: One identity has dominance over the other identities and anyone who shares the dominant identity is viewed as part of the in-group.

Example: If being a doctor is the dominant identity for Robert, then any other doctors are part of his in-group, regardless of their race, gender or seniority.

Compartmentalisation: The in-group changes depending on the social context.

Example: When working clinically on a hospital ward, Robert identifies as a doctor but when in a Board Meeting, his identity changes to being a senior leader.

Merging: The acceptance of anybody who holds any of the individual identities as part of the in-group

Example: Robert views all white men, all doctors and all senior healthcare leaders as members of the in-group.

Figure 1: Applying the Roccas and Brewer (2002) model of identity relation

Burford (2012) suggests that multiple identities relate to different areas of an individual's life (gender, ethnicity, occupation, hobbies) and that context determines the identity most relevant at any point. Identities can also be nested or hierarchical 
simultaneously, e.g. an individual may identify with the larger group of 'healthcare worker' whilst also identifying with the smaller group of 'doctor' or 'Medical Director'.

\section{Medical Professional Identity (MPI) and Medical Professional Identity Formation (MPIF)}

All individuals hold multiple identities, and for doctors, one of these is their MPI, formed through the process of MPIF which consists of three overlapping domains; professionalism, identity development and formation (Holden et al., 2012). It is increasingly recognised that whilst it is critical for doctors to acquire medical knowledge and skills, developing a sense of professionalism and professional identity is equally important (Burford, 2012; Goldie, 2012; Jarvis-Selinger et al., 2012; Monrouxe, 2010; Wald, 2015; Wilson, 2013). Professionalism and professional identity are quite separate concepts yet inextricably linked; professional identity is how an individual thinks of themselves as a doctor, whereas professionalism is displaying expected behaviours in six domains: ethical practice, reflection and selfawareness, responsibility for actions, respect for patients, teamwork and social responsibility (Hilton and Slotnick, 2005; Wilson, 2013). Having a strong professional identity helps individuals have confidence to display a "professional demeanour", thereby inspiring others to have confidence in their abilities (Monrouxe, 2010). Coulehan (2005) describes three different professional identities, an understanding of which can help educators guide individuals towards developing a desired professional identity:

- Compassionate and Responsive: The preferred professional identity; individuals accept and act in accordance with the traditionally accepted values of medical professionals

- Technical: Individuals adopt an identity in line with their organisation's culture, often manifesting as cynicism towards traditional medical values and a focus on the technical aspects of their role

- Non-Reflective: Individuals believe they adhere to traditional medical values but their behaviours reflect those with a technical professional identity and they lack awareness about their true identity 


\section{Medical Professional Identity Formation}

One of the main purposes of medical schools is to support the transition from "school student" to "medical student" to "doctor" through the development of professional identity (Wilson, 2013) during a period of "proto-professionalism" when professional behaviours are developed (Hilton and Slotnick, 2005) This process involves socialization, learning from role models, mentoring and experiential learning (Cruess et al., 2015). Whilst MPIF is a key part of undergraduate medical education, the process begins before university (Wilson, 2013) with medical students' I identity influenced by their backgrounds, values and experiences (Baernstein et al., 2009). Medical students are twice as likely as law students to have family members in the profession (Cavenagh, Dewberry and Jones, 2000) and medical television dramas influence students' beliefs about medical professionals (Weaver and Wilson, 2011). When students start medical school, they often feel isolated from other students due to differences in course structure, physical location of medical schools and a feeling of inclusivity on clinical placements. These factors influence medical students to form a "medical student" rather than "university student" identity (Weaver et al., 2011). Once MPIF is acquired, it must be maintained and adapted throughout life (Hilton and Slotnick, 2005). Doctors make frequent role transitions during postgraduate training and assume increasing clinical and leadership responsibilities. MPIF should therefore play an important part of continuing professional development which is often either overlooked or difficult to achieve in complex learning and working environments (Coulehan, 2005; Stern and Papadakis, 2006). For those taking on formal leadership and/or management roles, further development of their leader through MLIF, a concept we will introduce, becomes increasingly important.

\section{Identity Threats and Challenges}

Throughout their career, a doctor's MPI is subject to a number of threats and challenges at organisational, inter-personal and intra-personal levels.

\section{Organisational/System}

'Intersectionality' helps explain how multiple identities function and has relevance for medical leadership (Jones, 2003; Thomas and Crenshaw, 2004). Stemming originally from feminist studies and those of/by women of colour, intersectionality 
explains that our overlapping and intersecting identities are located within interlocking power systems. Because identity is closely linked to interconnected social categorisations (e.g. race/ethnicity, gender, class), intersectionality helps us understand some of the difficulties doctor-leaders might encounter, particularly in terms of perceived or actual discrimination or disadvantage. Power and privilege plays out in the medical leadership arena as the concept of 'leadership' and what leaders should look like and how they should behave, is in itself, socially constructed.

Moen et al's (2018) research into how senior doctors in training perceive clinical leadership and themselves as leaders (or not) reinforces that these doctors' views were clearly grounded in social constructs of leadership. These constructs of 'self' and 'leadership' were inhibiting factors in terms of how they saw themselves as leaders and their subsequent leadership development (Moen et al., 2018). This makes it harder for those who do not fit the 'leader' stereotype to be seen as credible and gain positions of influence, exacerbated by the lack of (e.g. women) senior role models. It is therefore important for organisations to recognise this potential barrier and to provide role-modelling opportunities within a culture of diverse and inclusive leadership (Inclusiveleadership.eu, 2019).

A further organisational challenge to MPI is that many doctors, particularly those in training, identify primarily with their profession rather than their organisation, which can lead to reduced medical engagement, "the active and positive contribution of doctors, within their normal working roles, to maintaining and enhancing the performance of the organisation" (Spurgeon et al., 2011). Lack of identification and engagement with their organisation may impede an organisation's ability to implement change (Leonard, 2003), and helping doctors in training feel like valued employees in their current organisation is therefore crucial.

The change in expectations of 'Generation $Y$ ' or 'Millennial' students and doctors in training (many of whom are women), who typically wish to have greater flexibility in their work-life balance (Curran, 2018), presents a further challenge. In the UK the Royal College of Physicians recently launched a pilot scheme for flexible portfolio careers where Higher Specialty Trainees can spend 20\% of their working week in 
either medical education, quality improvement, research or clinical informatics (RCP London, 2019), thereby integrating leadership skill development within clinical training. 'Generation $Y$ ' doctors might also find it difficult to identify with the older, established generation of doctors and doctor-leaders. As part of MPIF involves an individual's construction of 'the other' (Lingard et al, 2002), Generation Y doctors may view the older generation as 'others', creating an 'us' and 'them' scenario and challenging the traditional MPI.

Further challenges to MPIF come from the increasing diversity amongst medical students/doctors whilst the prevailing MPI has remained relatively traditional, resulting in discourse between diversity and MPIF standardisation (Fergus et al., 2018; Frost and Regehr, 2013). Some students/doctors embrace their individuality and create a new unique professional identity, which harnesses diversity but risks creating additional in and out-groups. Other students/doctors choose to weave aspects from the traditional professional identity with those from their social identity to create a hybrid identity, whilst others feel pressured to conform to a "standard" professional identity, which risks the medical profession losing its valuable diversity.

\section{Interpersonal}

Interpersonally, threats can be felt from the introduction of new roles, perceived as encroaching upon traditional professional boundaries. Expansion of existing roles (e.g. clinical nurse specialists) can seem threatening, but are contained within a preexisting profession and so may appear less threatening than new professions e.g. physician associates, 'who, while not a doctor, work to the medical model' (Department of Health, 2012). Conversely, in UK healthcare leadership and management, non-clinical 'professional' managers were recruited and trained to manage the NHS following the Griffiths Report (Griffiths, 1983) but now (often relatively unqualified) medical leaders are being encouraged to move into these 'professional manager' roles. Such blurring of role boundaries can be challenging for both groups (Lewis, 2014).

\section{Intrapersonal}

Intrapersonally, professional identity threats can arise from complaints (Allsop and Mulcahy, 1998), tighter professional regulation (Sullivan, 2000), and medical error 
that results in iatrogenic harm to patients (Kohn et al., 1999). Whether directly or implicitly challenging a doctor's professional knowledge, competence, and/or ability, these events can have significant effects, and where medical error is concerned, may lead to 'second victim' syndrome (Wu, 2000) which can drive a professional and identity crisis (Dekker, 2013).

Two theories help us understand some of the struggles doctor-leaders might face. Standpoint theory (Mann and Kelley, 1997) suggests each individual has a personal world view which includes a unique body of knowledge based on the geographic location and culture in which they developed. This can lead to feeling like an 'outsider within' (Collins 1986) or not 'belonging' in certain contexts and are powerful inhibitors to taking on leadership positions in certain contexts. Related to this is 'imposter syndrome', where individuals lack confidence in their abilities, fear failure and criticism, attribute achievements or success to 'luck' rather than ability, feel guilty about their 'success', and discount praise (Clance and Imes, 1978). Whilst the early research was carried out on high achieving women in business, more recent studies (including some in medicine) suggest it is not as gendered as first thought and that men are less likely to admit to these feelings (LaDonna et al 2018; Villwock et al 2016; Parkman 2016).

Taking on formal leadership/management positions and becoming a hybrid doctor manager (DM) (Spehar et al 2015; Kippist and Fitzgerald, 2014) can also threaten MPI because the traditional professional identities of doctors and managers are very different (Joffe and MacKenzie-Davey, 2012; Andersson, 2015). Doctor-leaders also report more difficulties in reconciling their physician and manager roles than nurses taking on managerial roles (Joffe and MacKenzie-Davey, 2012). This may be because doctors may perceive managers negatively, so maintaining clinical credibility is important for DMs in order to maintain the respect and followership of other doctors (Spehar et al 2015). Such hybrid leaders tend to keep their dominant professional identity as a doctor, rather than a leader/manager (Andersson, 2015) which can result in their leadership being clinically focused. When DMs reconcile both roles within their professional identity (Kippist and Fitzgerald, 2014) and form a strong MLI, they are more successful in bringing other doctors together to meet organisational objectives. 
The overriding challenge is how to support doctors to construct identities which incorporate leadership roles and help them develop an MLI more easily than the traditional MPI allows (Andersson, 2015). This includes consideration of when, how much and what to give up from their clinical work, which is central to their identity. Mentors already in medical leadership positions, and bodies such as the UK FMLM, can provide guidance for doctors making this transition.

\section{Response to threats and challenges}

Doctors can learn to 'customise' their MPI against challenges and threats through identity enriching, patching or splinting (Pratt et al., 2006). Identity enriching involves deepening understanding of one's professional identity e.g. through formal learning and reflection, whilst patching draws on knowledge of another professional identity to fill gaps in the understanding of your own professional identity (e.g. observing medical leaders in action). Splinting involves using a different temporary identity whilst an individual does not feel that a given professional identity fits (Pratt et al., 2006), for example doctors at the beginning of their leadership journey may temporarily identify as a 'student' or 'leadership fellow' rather than a "medical leader" despite actually being 'leaders'.

Being able to adapt or customise professional identity is important as in an increasingly global world, doctors often spend time working in different countries from where they trained, with different cultures and views of medical professionalism. Such doctors need to be able to adapt their MPI to integrate within new workplaces and become part of the "in-group" (Helmich et al., 2017; McKimm and Wilkinson, 2015). Clinicians who take on formal leadership roles must also adapt their MPI so as to identify, communicate and collaborate effectively with both doctors and managers. Doctor-leaders therefore need to build reflexivity into their MPI to be able to seize opportunities without this being seen as an identity threat (Sullivan, 2000).

\section{Introducing Medical Leader Identity (MLI) and Medical Leader Identity Formation (MLIF)}


Whilst MPI is clearly crucial, with the increasing focus on medical leadership Dickson and Owen, 2016) (Kyratsis et al., 2016), we suggest that developing a strong MLI is equallyimportant. Doctors taking a 'clinical' lead (i.e. being accountable for clinical care) has long been embedded in standards and curricula (e.g. General Medical Council, 2018) but medical leadership is being redefined and expanded beyond accountability for direct patient care, towards healthcare advocacy roles (Frank et al., 2015) and a wider leadership and management role (General Medical Council, 2012). The shift to incorporate generic competencies (such as leadership) is not without danger to the newly constructed MPI, and can lead to loss of confidence, stress and burnout (Westerman et al., 2013). If doctors can form an MLI which incorporates both their "doctor" and "leader" identities, they can make successful healthcare leaders more likely to be seen as part of the "in-group" by other doctors, who generally see non-clinical managers as the "out-group" and may be less likely to follow their lead (Mannion et al 2015).

Depending on how MLI is conceptualised, individuals may need to significantly adjust their existing MPI through enriching, patching or splinting their identity (Pratt et al., 2006) to include their leadership roles, or develop an entirely new 'leader' identity to sit alongside their other identities. Identity formation involves a constant construction, deconstruction and reinterpretation, and opportunities must be created and encouraged for these processes to occur (Wald, 2015). MLIF, similarly to MPIF, is an ongoing process through which individuals develop their identity as a medical leader based upon their world view, which both influences and is influenced by their social and personal identities and openness to, and reflections upon, experiences (Figure 1). 


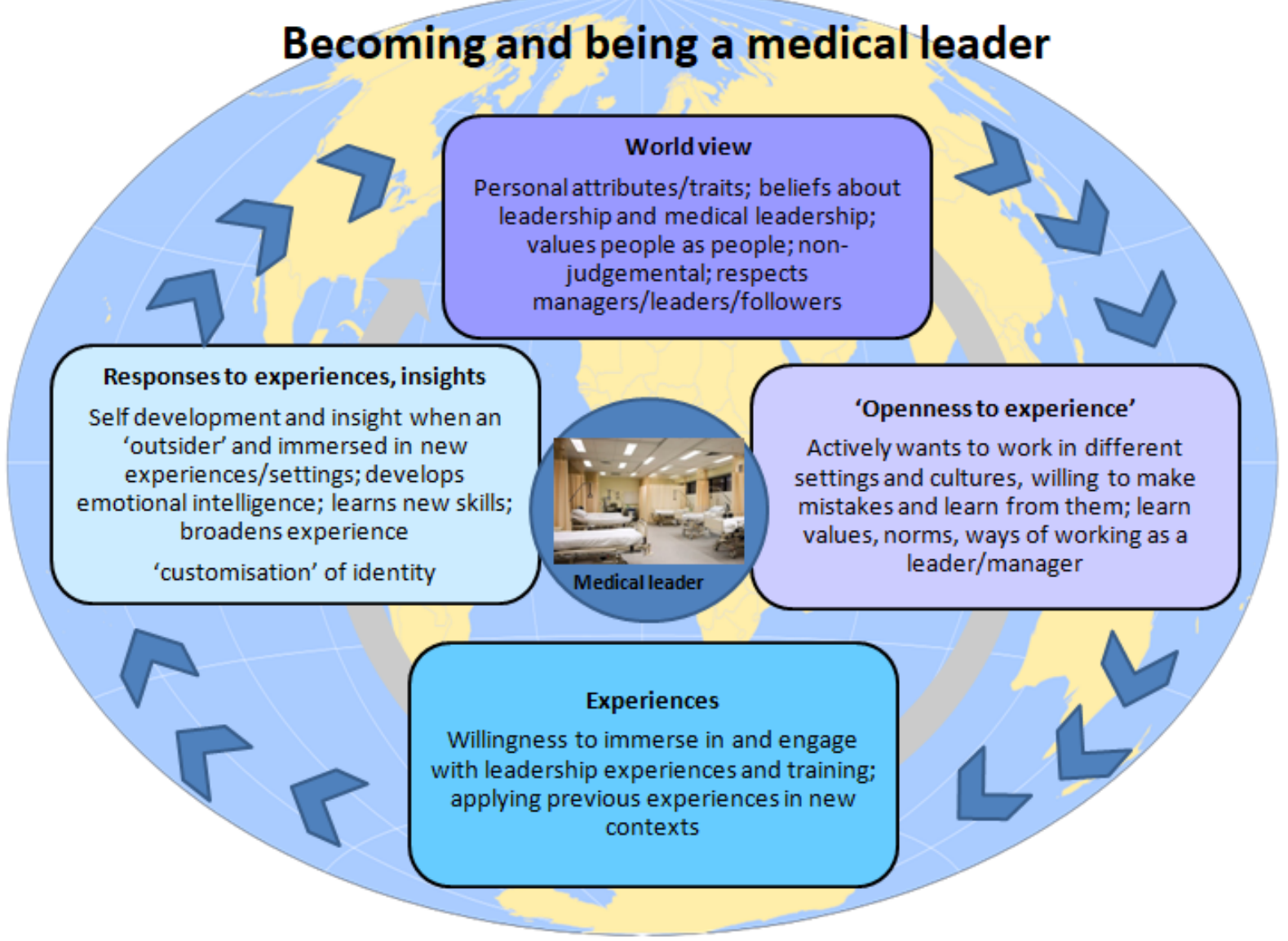

Figure 1: Becoming and being a medical leader

Just as the professional identity of medical students begins before medical school, an individual's view of leaders and leadership is similarly influenced by the media, role models and stereotypes. 'Implicit leadership theories' suggest we hold strong internal beliefs about what leaders (and followers) should look like, often unarticulated and out of conscious awareness (Scott et al 2017; Mannion et al 2015). The influence of early socialisation and the media influence beliefs about what makes a 'good' leader, prior to individuals taking on any leadership roles themselves. Whilst students/doctors seem to relatively easily incorporate 'clinical leadership' (of situations, teams etc.) into their doctor identity, forming a strong identity as a leader and manager (of services and organisations) seems less straightforward (Moen et al., 2018; Spurgeon and Ham, 2017; Gordon et al 2015). 


\section{Opportunities for Medical Leader Identity Formation and Implications for Medical Education \& Training}

The fluid development of professional and leadership identities means that opportunities must be created in both undergraduate and postgraduate medical education for individuals to develop, understand and reflect upon their identities (Moen et al 2018). The ongoing nature of MLIF also means that as with MPI, MLI is subject to the threats and challenges previously discussed, which organisations and medical educators must recognise in order to support individuals who may find their identity challenged. Here we identify a number of opportunities for the development of both MPI and MLI within medical practice.

The Hidden Curriculum: Whilst formal identity and leadership developmental opportunities are important, the 'hidden curriculum', comprising informal interactions between seniors, peers and near-peers is most influential (Goldie, 2012; Gaufberg et al., 2010). Providing 'little l' leadership (Bohmer, 2010) opportunities (e.g. leading a ward round or project) can help doctors and students develop their leadership skills and provide them with situations in which they can experiment with their 'provisionalselves' to become more aware of who they are and who they want to be (Ibarra, 1999). Provided this occurs within a psychologically safe environment (Edmondson, 1999), medical professionals can self-evaluate their performance against feedback and their own internal standards to hone both their MLI and MPI.

Opportunities in clinical practice: There are numerous opportunities for identity development in everyday clinical practice, and activities should be optimised to help doctors develop their leadership skills, although healthcare organisations are not always good at engaging trainees in meaningful leadership development, and leadership and management development at organisational level is often patchy (Miller et al., 2018). Higher quality care is provided when healthcare professionals work in multi-disciplinary teams (Borrill et al., 2000) and professionals learn more when working co-operatively (Slavin, 1983). Interprofessional learning (IPL) is important for developing each individual's own professional identity, to better understand the roles and identities of others, and learn that doctors must follow as 
well as lead (Lingard et al., 2002). Focusing on their wider identities as 'healthcare professionals' (rather than doctors or nurses) can also be helpful to appreciate shared attributes and characteristics, and reduce interprofessional rivalry (Burford, 2012). Targeted educational interventions (e.g. case-based teaching) enable different health professionals/students to work together and further develop their professional identities (Apker and Eggly, 2004; Lingard et al., 2003).

Narrative reflection: Medical professionals must develop self-insight into their strengths, weaknesses, values, attitudes and beliefs, and narrative reflection can be used to facilitate this learning about their identity, strengths and areas for development (Moen et al 2018; Ricoeur, 1992). Reflective writing has been used alongside training on mindfulness, resilience and wellbeing to support MPIF and move away from a focus on "doing the work of a doctor" to "being a doctor" (Wald et al., 2015). Analysis of medical student reflections identified five key influences on MPIF: prior experiences, role models, patient encounters, curriculum (formal and hidden) and societal expectations (Wong and Trollope-Kumar, 2014). Reflection can also be in the form of a structured significant event (or 'heat' experience (Petrie 2014)) analysis which helps facilitate understanding about what happened, and what they could do differently in the future (Clandinin and Cave, 2008). Similarly, group reflections help develop relationships which contribute to wellbeing and resilience and form a positive reciprocal feedback loop which contributes to MPIF (Clandinin and Cave, 2008; Wilson, 2013). We suggest that narrative reflection should also be used to help doctors develop their MLI. Indeed, most formal medical leadership programmes require participants to undertake some form of leadership activity followed by analysis, reflection and sharing practice with others (Clapp et al 2018).

External Validation: MPIF is further developed through formal rites of passage and external validation (Goldie, 2012) including simple interventions such as job titles, name badges and uniforms(Professional Standards Authority, 2016). Medical graduation ceremonies, gaining postgraduate qualifications (Sethi et al., 2018) and informal situations such as access to the doctors' mess or working through the night (Monrouxe, 2010) also influence MPIF and a feeling of belonging to their profession. It has also been suggested that medical leaders holding externally validated formal leadership positions may be more likely to adjust their MPI to include their leadership 
role than medical leaders with informal leadership roles (Berghout et al., 2017). The FMLM Leadership and Management Standards for Medical Professionals (FMLM, 2016) provides all doctors with a means of acquiring external validation for their leadership and management activities and is supported by a 360 feedback tool (FMLM, 2018b) which may encourage all doctors to reframe their activities in terms of leadership and incorporate this into their MLI.

Assessment: With the increasing recognition of the importance of MPI in medical education, curricula and assessment tools are now being developed (Holden et al., 2015; Cruess et al., 2014). For example, the four levels of Miller's pyramid of assessing medical competence (Miller, 1990) - "knows", "knows how", "shows how" and "does" - have been expanded to include a fifth level ("is") which acknowledges the presence or absence of a MPI (Cruess, et al 2016). The "novice to expert model of professional competence" (Flower, 1999) has also been adapted to map leadership, implicit leadership theory, social identity, self-efficacy, theories of self, followership and teamwork to the model, acting as a framework for medical educators to design and facilitate activities which enable these areas to be explored and assessed, and MPI to be developed (McKimm, et al 2017). The Professional Identity Essay (PIE) (Bebeau and Monson, 2012) measures the extent to which individuals understand their professional role and the Professional Identity Scale (Adams et al., 2006) indicates that a strong sense of MPI is associated with lower levels of burnout (Monrouxe et al., 2017). The continued development and use of such assessment methods is crucial for organisations to understand the impact of various interventions upon MPIF/MLIF.

\section{Conclusions}

Doctors' medical professional identity begins to form before medical school and is influenced, shaped, threatened and challenged throughout their career. Identity formation is fluid and complex in nature and requires nurturing throughout the continuum of education and training through the provision of formal and informal opportunities for the development of, and reflection on, appropriate professional identities with the recognition that these identities are multiple, nested and interconnected, and must change and adapt over time. 
Doctors do more than just technical work, they must truly "be" doctors and increasingly they are also now required to "be" medical leaders. It cannot however be assumed that doctors will automatically and easily take on leadership and management roles that are not traditionally seen as a part of the doctor role, due to how this may threaten or challenge their MPI, if they have not had the opportunity to absorb leadership into their identity, or developed a new MLI

It is therefore crucial that alongside providing opportunities for the development of traditional MPI, opportunities for the specific development and assessment of MLI are also created. If doctors are to develop meaningful MLIs so that they can better take on leadership and management roles, they need good medical leader role models, mentoring and shadowing opportunities, formal training, recognition which professionalises doctors as leader-managers, and support and feedback in the workplace for developing and engaging in leadership. Such support will help to nurture the next generation of medical leaders who see healthcare leadership as an intrinsic part of their professional identity as a doctor. 


\section{References}

Adams, K., Hean, S., Sturgis, P. and Clark, J. (2006). Investigating the factors influencing professional identity of first-year health and social care students. Learning in Health and Social Care, 5(2), pp.55-68.

Allsop, J. and Mulcahy, L. (1998). Maintaining Professional Identity: Doctors' Responses to Complaints. Sociology of Health and IIIness, 20(6), pp.802-824.

Andersson, T. (2015). The medical leadership challenge in healthcare is an identity challenge. Leadership in Health Services, 28(2), pp.83-99.

Apker, J. and Eggly, S. (2004). Communicating Professional Identity in Medical Socialization: Considering the Ideological Discourse of Morning Report. Qualitative Health Research, 14(3), pp.411-429.

Baernstein, A., Oelschlager, A., Chang, T. and Wenrich, M. (2009). Learning Professionalism: Perspectives of Preclinical Medical Students. Academic Medicine, 84(5), pp.574-581.

Bebeau, M.J. and Monson, V.E., (2012). Professional identity formation and transformation across the life span. In Learning trajectories, innovation and identity for professional development (pp. 135-162). Springer, Dordrecht.

Burford, B. (2012). Group processes in medical education: learning from social identity theory. Medical Education, 46(2), pp.143-152.

Berghout, M., Fabbricotti, I., Buljac-Samardžić, M. and Hilders, C. (2017). Medical leaders or masters? A systematic review of medical leadership in hospital settings. PLOS ONE, 12(9), p.e0184522.

Bohmer, R. (2010). Leadership with a small" I". BMJ: British Medical Journal (Online), 340. 
Borrill, C., West, M., Shapiro, D. and Rees, A., (2000). Team working and effectiveness in health care. British Journal of Healthcare Management, 6(8), pp.364-371.

Burford, B., (2012). Group processes in medical education: learning from social identity theory. Medical education, 46(2), pp.143-152.

Burke, P. and Stets, J. (2009). Identity theory. New York: Oxford University Press.

Cavenagh, P., Dewberry, C. and Jones, P. (2000). Becoming professional: when and how does it start? A comparative study of first-year medical and law students in the UK. Medical Education, 34(11), pp.897-902.

Clandinin, D. and Cave, M. (2008). Creating pedagogical spaces for developing doctor professional identity. Medical Education, 42(8), pp.765-770.

Clance, PR.; Imes, SA. (1978). "The Impostor Phenomenon in High Achieving Women: Dynamics and Therapeutic Intervention" (PDF). Psychotherapy Theory, Research and Practice. 15 (3). doi:10.1037/h0086006.

Clapp, J. T., Gordon, E. K., Baranov, D. Y., Trey, B., Tilin, F. J., \& Fleisher, L. A. (2018). Encouraging reflexivity in a residency leadership development program: Expanding outside the competency approach. Academic Medicine, 93(2), 210-213.

Collins, P.H. (1986). "Learning from the outsider within: the sociological significance of black feminist thought". Social Problems. Oxford University Press. 33 (6): s14s32. doi:10.2307/800672. JSTOR 800672.

Cote, J. and Levine, C. (2002). Identity, Formation, Agency, and Culture.

Coulehan, J., (2005). Today's Professionalism: Engaging the Mind but Not the Heart. Academic medicine, 80(10), pp.892-898. 
Cruess, R., Cruess, S., Boudreau, J., Snell, L. and Steinert, Y. (2014). Reframing Medical Education to Support Professional Identity Formation. Academic Medicine, 89(11), pp.1446-1451.

Cruess, R., Cruess, S., Boudreau, J., Snell, L. and Steinert, Y. (2015). A Schematic Representation of the Professional Identity Formation and Socialization of Medical Students and Residents. Academic Medicine, 90(6), pp.718-725.

Cruess, R., Cruess, S. and Steinert, Y. (2016). Amending Miller's Pyramid to Include Professional Identity Formation. Academic Medicine, 91(2), pp.180-185.

Curran, P. (2018). Review Body on Doctors' and Dentists' Remuneration Forty-Fifth Report 2017. [online] Available at:

https://www.gov.uk/government/publications/review-body-on-doctors-and-dentistsremuneration-45th-report-2017 [Accessed 16 Oct. 2018].

Dekker., S. (2013). Second Victim: Error, Guilt, Trauma and Resilience. Florida: CRC Press

Department of Health (2012) Physician Assistant Managed Voluntary Register: Competence and Curriculum Framework for the Physician Assistant. London: Department of Health

Dickson, G. and Owen, K. (2016). Editorial. Leadership in Health Services, 29(3), pp.218-219.

Edmondson, A. (1999). Psychological Safety and Learning Behavior in Work Teams. Administrative Science Quarterly, 44(2), p.350.

Eriksen, K. (2006). The Constructive Developmental Theory of Robert Kegan. The Family Journal, 14(3), pp.290-298.

Faculty of Medical Leadership and Management (2016) Leadership and management standards for medical professionals (2nd ed.), London: Faculty of 
Medical Leadership and Management. Available at https://www.fmlm.ac.uk/individual-standards (accessed 25 July 2018)

Fergus, K., Teale, B., Sivapragasam, M., Mesina, O. and Stergiopoulos, E. (2018). Medical students are not blank slates: Positionality and curriculum interact to develop professional identity. Perspectives on Medical Education, 7(1), pp.5-7.

FMLM (2018a). Background | Faculty of Medical Leadership and Management. [online] Available at: https://www.fmlm.ac.uk/about-us/who-we-are/background [Accessed 17 Jul. 2018].

FMLM (2018b) Medical leadership and Management: An indicative undergraduate curriculum. Available at https://www.fmlm.ac.uk/sites/default/files/content/news/attachments/Medical\%20lead ership\%20and\%20management $\% 20$ -

\%20an\%20indicative\%20undergraduate\%20curriculum.pdf (accessed 29 March 2019)

FMLM (2018b). FMLM 360 | Faculty of Medical Leadership and Management. [online] Available at: https://www.fmlm.ac.uk/programme-services/individualsupport/fmlm-360 [Accessed 16 Oct. 2018].

Flower, J., 1999. In the mush. Physician executive, 25(1), pp.64-66.

Frost, H. and Regehr, G. (2013). "I AM a Doctor". Academic Medicine, 88(10), pp.1570-1577.

Frank JR, Snell L, Sherbino J, editors. (2015) CanMEDS 2015 Physician Competency Framework. Ottawa: Royal College of Physicians and Surgeons of Canada.

Frost, H.D. and Regehr, G., (2013). "I am a doctor": negotiating the discourses of standardization and diversity in professional identity construction. Academic Medicine, 88(10), pp.1570-1577. 
General Medical Council (2018) Outcomes for graduates 2018. Available at https://www.gmc-uk.org/-/media/documents/dc11326-outcomes-for-graduates2018_pdf-75040796.pdf (accessed 25 July 2018)

General Medical Council (2012) Leadership and management for all doctors. Available at https://www.gmc-uk.org/-/media/documents/leadership-and-management-for-alldoctors---english-1015_pdf-48903400.pdf (accessed 25 July 2018)

Gaufberg, E.H., Batalden, M., Sands, R., et al., (2010) The hidden curriculum: what can we learn from third-year medical student narrative reflections? Acad. Med. 85 (11):1709-1716.

Goldie, J. (2012). The formation of professional identity in medical students: Considerations for educators. Medical Teacher, 34(9), pp.e641-e648.

Gordon, L. J., Rees, C. E., Ker, J. S., \& Cleland, J. (2015). Leadership and followership in the healthcare workplace: exploring medical trainees' experiences through narrative inquiry. BMJ open, 5(12), e008898.

Griffiths, R., (1983). NHS management inquiry: report to the secretary of state for social services. Department of Health and Social Security, London.

Helmich, E., Yeh, H., Kalet, A. and Al-Eraky, M. (2017). Becoming a Doctor in Different Cultures. Academic Medicine, 92(1), pp.58-62.

Hilton, S. and Slotnick, H. (2005). Proto-professionalism: how professionalisation occurs across the continuum of medical education. Medical Education, 39(1), pp.5865.

Hogg, M.A., Terry, D.J. and White, K.M., (1995). A tale of two theories: A critical comparison of identity theory with social identity theory. Social psychology quarterly, pp.255-269. 
Holden, M., Buck, E., Clark, M., Szauter, K. and Trumble, J. (2012). Professional Identity Formation in Medical Education: The Convergence of Multiple Domains. HEC Forum, 24(4), pp.245-255.

Holden, M., Buck, E., Luk, J., Ambriz, F., Boisaubin, E., Clark, M., Mihalic, A., Sadler, J., Sapire, K., Spike, J., Vince, A. and Dalrymple, J. (2015). Professional Identity Formation: Creating a Longitudinal Framework Through TIME (Transformation in Medical Education). Academic Medicine, 90(6), pp.761-767.

House, J. (1977). The Three Faces of Social Psychology. Sociometry, 40(2), p.161.

Ibarra, H. (1999). Provisional Selves: Experimenting with Image and Identity in Professional Adaptation. Administrative Science Quarterly, 44(4), p.764.

Inclusiveleadership.eu. (2019). Inclusive Leadership. [online] Available at: https://inclusiveleadership.eu/ [Accessed 28 Mar. 2019].

Jarvis-Selinger, S., Pratt, D. and Regehr, G. (2012). Competency Is Not Enough. Academic Medicine, 87(9), pp.1185-1190.

Jenkins, R., 2008. Social Identity. 3rd ed. New York: Routledge.

Joffe, M. and MacKenzie-Davey, K. (2012). The problem of identity in hybrid managers: who are medical directors?. International Journal of Leadership in Public Services, 8(3), pp.161-174.

Jones, Sandra J. (2003). "Complex subjectivities: class, ethnicity, and race in women's narratives of upward mobility". Journal of Social Issues. Wiley. 59 (4): 803820. doi:10.1046/j.0022-4537.2003.00091.x.

Kippist, L. and Fitzgerald, A. (2014). Professional Identity: Enabler or Barrier to Clinical Engagement?. Employment Relations Record, 14(2), pp.27-48. 
Kohn, L.T., Corrigan, J.M., Donaldson, M.S. (1999) To err is human: building a safer health system. US: National Academies Press

Kyratsis, Y., Armit, K., Zyada, A. and Lees, P. (2016). Medical leadership and management in the United Kingdom. Australasian Psychiatry, 24(3), pp.240-242.

LaDonna, K. A., Ginsburg, S., \& Watling, C. (2018). "Rising to the Level of Your Incompetence": What Physicians' Self-Assessment of Their Performance Reveals About the Imposter Syndrome in Medicine. Academic Medicine, 93(5), 763-768.

Leonard, P. (2003). 'Playing' Doctors and Nurses? Competing Discourses of Gender, Power and Identity in the British National Health Service. The Sociological Review, 51(2), pp.218-237.

Lewis, R. (2014) Future of NHS: Thirty years on, the Griffiths Report makes interesting reading, Health Service Journal, available at https://www.hsj.co.uk/futureof-nhs-leadership/thirty-years-on-the-griffiths-report-makes-interestingreading/5072885.article

Lingard, L., Reznick, R., DeVito, I. and Espin, S. (2002). Forming professional identities on the health care team: discursive constructions of the 'other' in the operating room. Medical Education, 36(8), pp.728-734.

Lingard, L., Garwood, K., Schryer, C. and Spafford, M. (2003). A certain art of uncertainty: case presentation and the development of professional identity. Social Science \& Medicine, 56(3), pp.603-616.

Mann, S.A., Kelley, L.R. (1997). "Standing at the crossroads of modernist thought: Collins, Smith, and the new feminist epistemologies". Gender \& Society. Sage. 11 (4): 391-408. doi:10.1177/089124397011004002.

Mannion, H., McKimm, J. and O'Sullivan, H. (2015). Followership, clinical leadership and social identity. British Journal of Hospital Medicine, 76(5), pp.270-274. 
McKimm, J. and Wilkinson, T. (2015). "Doctors on the move": Exploring professionalism in the light of cultural transitions. Medical Teacher, 37(9), pp.837843.

McKimm, J., Vogan, C. and Mannion, H. (2017). Implicit leadership theories and followership informs understanding of doctors' professional identity formation: A new model. The Asia Pacific Scholar, 2(2), pp.18-23.

Miller, G. (1990). The assessment of clinical skills/competence/performance. Academic Medicine, 65(9), pp.S63-7.

Miller, C. J., Till, A., and McKimm, J. (2018). Exploring UK health-care providers' engagement of trainee doctors in leadership. British Journal of Hospital Medicine, 79(5), 279-283.

Moen C, Brown J, Kaehne A. Exploration of 'perception of self'as medical leader: does perception of self require a paradigm shift from clinician to clinical leader?. BMJ Leader. 2018 Sep 1;2(3):103-9.

Monrouxe, L. (2010). Identity, identification and medical education: why should we care?. Medical Education, 44(1), pp.40-49.

Monrouxe, L., Bullock, A., Tseng, H. and Wells, S. (2017). Association of professional identity, gender, team understanding, anxiety and workplace learning alignment with burnout in junior doctors: a longitudinal cohort study. BMJ Open, 7(12), p.e017942.

Parkman, A., (2016) The imposter syndrome in higher education: Incidence and impact. Journal of Higher Education Theory and Practice, 16(1), 51-60

Peake, L.K. and Swanwick, T., 2018. Tomorrow's Leaders, Today: leadership and management in the undergraduate curriculum. BMJ Leader, 2(1), pp.10-11. 
Petrie, N. (2014). Vertical leadership development-part 1 developing leaders for a complex world. Center for Creative Leadership.

Pratt, M., Rockmann, K. and Kaufmann, J. (2006). Constructing professional identity: The role of work and identity learning cycles in the customization of identity among medical residents. Academy of Management Journal, 49(2), pp.235-262.

Professional Standards Authority (2016). Professional identities and regulation: a Literature Review.

Racma.edu.au. (2019). Medical Leadership and Management Curriculum. [online] Available at: https://racma.edu.au/page/resources/medical-leadership-andmanagement-curriculum [Accessed 28 Mar. 2019].

Ricoeur P (1992) Oneself as another (K Blamey, Trans.) Chicago: University of Chicago Press

Roccas, S. and Brewer, M. (2002). Social Identity Complexity. Personality and Social Psychology Review, 6(2), pp.88-106.

Royalcollege.ca. (2019). The Royal College of Physicians and Surgeons of Canada :: CanMEDS Framework. [online] Available at:

http://www.royalcollege.ca/rcsite/canmeds/canmeds-framework-e [Accessed 28 Mar. 2019].

Scott, C. P., Jiang, H., Wildman, J. L., \& Griffith, R. (2017). The impact of implicit collective leadership theories on the emergence and effectiveness of leadership networks in teams. Human Resource Management Review.

Sethi, A., Schofield, S., McAleer, S. and Ajjawi, R. (2018). The influence of postgraduate qualifications on educational identity formation of healthcare professionals. Advances in Health Sciences Education.

Sheriff I.H.N., Ahmed, F., Jivraj, N., Wan J.C.M., Sampford, J., Ahmed, N. (2017) 
Student-led leadership training for undergraduate healthcare students, Leadership in Health Services, 30(4), pp.428431, https://doi.org/10.1108/LHS-03-2017-0018

Slavin, R.E. (1983). When does cooperative learning increase student achievement?. Psychological bulletin, 94(3), p.429.

Spehar, I., Frich, J., and Kjekshus, L. (2015). Professional identity and role transitions in clinical managers. Journal of Health Organization and Management, 29(3), pp.353-366.

Spurgeon, P., Clark, J., \& Ham, C. (2017). Medical leadership: from the dark side to centre stage. CRC Press.

Spurgeon, P., Mazelan, P.M. and Barwell, F. (2011). Medical engagement: a crucial underpinning to organizational performance. Health Services Management Research, 24(3), pp.114-120.

Stern, D. and Papadakis, M. (2006). The Developing Physician - Becoming a Professional. New England Journal of Medicine, 355(17), pp.1794-1799.

Stets, J.E. and Burke, P.J. (2000). Identity theory and social identity theory. Social psychology quarterly, pp.224-237.

Sullivan, W.M., (2000). Medicine under threat: professionalism and professional identity. Canadian Medical Association Journal, 162(5), pp.673-675.

Till, A., McKimm, J., and Swanwick, T. (2017). Twelve tips for integrating leadership development into undergraduate medical education. Medical Teacher, pp.1-7.

Thomas, S. and Crenshaw, K. (Spring 2004). "Intersectionality: the double bind of race and gender" (PDF). Perspectives Magazine. American Bar Association. p. 2. 
Tricco AC, Antony J, Zarin W, Strifler L, Ghassemi M, Ivory J, Perrier L, Hutton B, Moher D, Straus SE. A scoping review of rapid review methods. BMC medicine. 2015 Dec;13(1):224.

Villwock, J. A., Sobin, L. B., Koester, L. A., \& Harris, T. M. (2016). Impostor syndrome and burnout among American medical students: a pilot study. International journal of medical education, 7, 364.

Wald, H. (2015). Professional Identity (Trans)Formation in Medical Education. Academic Medicine, 90(6), pp.701-706.

Wald, H., Anthony, D., Hutchinson, T., Liben, S., Smilovitch, M. and Donato, A. (2015). Professional Identity Formation in Medical Education for Humanistic, Resilient Physicians. Academic Medicine, 90(6), pp.753-760.

Weaver, R., Peters, K., Koch, J. and Wilson, I. (2011). 'Part of the team': professional identity and social exclusivity in medical students. Medical Education, 45(12), pp.1220-1229.

Weaver, R. and Wilson, I. (2011). Australian medical students' perceptions of professionalism and ethics in medical television programs. BMC Medical Education, 11(1).

Westerman M, Teunissen P, Fokkema J, van der Vleuten C, Scherpbier A, Siegert C, Scheele F. 2013. The transition to hospital consultant and the influence of preparedness, social support and perception: a structural equation modelling approach. Medical Teacher. 35(4):320-327.

Wilson, I., Cowin, L., Johnson, M. and Young, H. (2013). Professional Identity in Medical Students: Pedagogical Challenges to Medical Education. Teaching and Learning in Medicine, 25(4), pp.369-373.

Wong, A. and Trollope-Kumar, K. (2014). Reflections: an inquiry into medical students' professional identity formation. Medical Education, 48(5), pp.489-501. 
$\mathrm{Wu}, \mathrm{AW}$. Medical error: the second victim. The doctor who makes the mistake needs help too. BMJ 2000;320:726-7. 